\title{
MYCORRHIZA-INDUCED ALLEVIATION OF PLANT DISEASE CAUSED BY CLAVIBACTER MICHIGANENSIS SUBSP. MICHIGANENSIS AND ROLE OF ETHYLENE IN MYCORRHIZA-INDUCED RESISTANCE IN TOMATO
}

\author{
Nguyen Hong Duc and Katalin Posta* \\ Institute of Genetics, Microbiology and Biotechnology, Szent István University, \\ Páter Károly út 1, Gödöllö H-2100, Hungary
}

(Received: August 4, 2017; accepted: April 3, 2018)

\begin{abstract}
The protective role of arbuscular mycorrhizal fungi (AMF) against the phytopathogen Clavibacter michiganensis subsp. michiganensis $(\mathrm{Cmm})$ was examined in tomato plants. Seven different AMF isolates were used to determine which ones were able to induce effectively resistance against $\mathrm{Cmm}$. Stems of seven-week tomato plants were infected with $\mathrm{Cmm}$, then a disease severity index (DSI) was determined during the next three weeks. In addition to different responses to mycorrhizal inoculation, three levels of responses to the bacterial disease were recognized in treatments. Plants inoculated with Rhizophagus irregularis (Ri) showed both the highest colonization and the highest induced resistance to Cmm while the effect of Funneliformis mosseae, Gigaspora margarita and Claroideoglomus claroideum on mycorrhizal colonization and on the induced resistance were intermediate and high, respectively. Subsequently, Ri was chosen to inoculate ethylene-insensitive tomato mutant line Never ripe (Nr) and its background (Pearson) to investigate the possible role of ethylene (ET) in the mycorrhiza-induced resistance (MIR). The results showed that Ri could induce systemic resistance against $\mathrm{Cmm}$ in the Pearson background, whereas ET-insensitivity in $\mathrm{Nr}$ plants impaired MIR. These results suggest that ET is required for Ri-induced resistance against $\mathrm{Cmm}$. To our knowledge, this is the first study to examine the effect of different AMF isolates on the response of tomato plants to $\mathrm{Cmm}$ and involvement of ET in MIR against $\mathrm{Cmm}$.
\end{abstract}

Keywords: Clavibacter michiganensis subsp. michiganensis - arbuscular mycorrhizal fungi - mycorrhiza-induced resistance - tomato - ethylene

\section{INTRODUCTION}

Tomato is an important vegetable plant cultivated under a wide range of production system throughout the world. However, tomato production worldwide incurs severe yield losses by the most important bacterial disease Clavibacter michiganensis subsp.

Abbreviations: AM, arbuscular mycorrhizal; AMF, arbuscular mycorrhizal fungi; Cmm, Clavibacter michiganensis subsp. michiganensis; Cc, Claroideoglomus claroideum; DSI, disease severity index; ET, ethylene; Fg, Funneliformis geosporum; Fm, Funneliformis mosseae; Gm, Gigaspora margarita; MIR, mycorrhiza-induced resistance; Sc, Septoglomus constrictum; Ri, Rhizophagus irregularis; Rs, Rhizophagus sp.

* Corresponding author; e-mail address: Posta.Katalin@mkk.szie.hu 
michiganensis (Cmm). It is a causal agent of the wilt and canker disease [7], as well as one of quarantine organisms that are subject to international quarantine regulations. Arbuscular mycorrhizal (AM) symbiosis is the most ubiquitous mutualistic association formed between arbuscular mycorrhizal fungi (AMF) and plant roots. In addition to improved water and nutrient uptake in the host plant, AMF could enhance plant resistance against various pathogens [17]. Indeed, many studies describe that mycorrhizal colonization increases plant resistance against pathogenic fungi and bacteria $[10,24,30,38]$.

The use of arbuscular mycorrhizal fungi provides a sustainable alternative for plant disease management [21]; however, the underlying mechanism of AMF-induced disease resistance remains elusive. Most studies focused on only a single isolate or a few AMF species (mostly Glomus intraradices and G. mosseae), giving conflicting reports on the specificity of AMF. Despite evidences of AMF potential in controlling plant diseases, little attention has been paid to the effects of mycorrhization on plant resistance to $\mathrm{Cmm}$. There is a only single work demonstrating a neutral effect of extraradical mycelium of $G$. intraradices on the growth of Cmm [9].

Plant defense responses highly rely on its hormones to coordinate a complex defense system to combat against pathogens. Among phytohormones, ethylene (ET) plays an essential role in the regulation of plant immunity [2], and a significant role in microbe-plant interactions [18]. During Cmm infection, ET has been proved to be crucial in the development of wilting and canker symptoms [4]. Many studies highlight that resistance against a wide range of phytopathogens induced by beneficial microbes largely depends on the Jasmonate/ET signalling pathway [15, 19, 42].

The objectives of this study were to reveal out whether AMF isolates were able to induce systemic resistance to $\mathrm{Cmm}$ in tomato plants, if so, a possible role of ET signalling pathway in mycorrhiza-induced resistance (MIR).

\section{MATERIALS AND METHODS}

\section{Preparation of different AM inoculums}

Mycorrhiza inoculums including seven different AMF species were propagated separately in pot cultures of Zea mays and Medicago truncatula for 9 months. The basic AMF samples, Funneliformis mosseae BEG 12 (Fm), Funneliformis geosporum BEG 11 (Fg), Rhizophagus irregularis MUCL43194 (DAOM197198) (Ri), Rhizophagus sp. MUCL43204 (Rs), Septoglomus constrictum (formerly Glomus constrictum Trappe.) (Sc), Claroideoglomus claroideum BEG 23 (Cc), Gigaspora margarita BEG $34(\mathrm{Gm})$ originated from different national mycorrhizal collections. Mycorrhizal inoculums consisted of sand, mycelia, infected root fragments and spores. Spores of each AMF species in inoculums were examined and adjusted to 22 spores/g on average before inoculation. Thirty grams of inoculum were placed at $3 \mathrm{~cm}$ below pregerminated seeds in plastic pots at the time of transferring the seeds. Non-AM plants 
were received thirty grams of autoclaved mycorrhizal inoculum and $3 \mathrm{ml}$ aliquot of a filtrate $(<20 \mu \mathrm{m})$ of the AM inoculum to supply a general microbial population free of AM propagules.

\section{Plant material and growth conditions}

Two consecutive experiments were conducted as followings.

\section{Experiment 1: Effect of different AMF isolates on tomato plant resistance against $\mathrm{Cmm}$}

Tomato seeds (Solanum lycopersicum L. cv. MoneyMaker) were treated with $2.7 \%$ sodium hypochlorite containing $0.02 \%$ (v/v) Tween-20 for $30 \mathrm{~min}$, then washed with sterilized distilled water several times, and put on the filter paper in Petri dishes at $26^{\circ} \mathrm{C}$ for 3 days for germination. Pre-germinated seeds were sown in each plastic pot containing $0.5 \mathrm{~kg}$ of sterile sand:peat $(4: 1, \mathrm{v} / \mathrm{v})$ mixture. Before planting the seeds, different mycorrhizal inoculations, representing different treatments were prepared. There were eight treatments including plants inoculated separately with one of seven different AMF isolates altogether with non-AM plants. Thirty replicates of each treatment settled in a growth chamber. Pots were randomly distributed and cultivated at $23 / 28{ }^{\circ} \mathrm{C}$ with $16 / 8$ hours of photoperiod, light intensity of $600 \mu \mathrm{mol} / \mathrm{m}^{2} / \mathrm{s}$ and $60 \%$ humidity. Pots were watered twice and fertilized once a week with Long Ashton nutrient solution [14], adjusted to $3.2 \mu \mathrm{M} \mathrm{Na}_{2} \mathrm{HPO}_{4} \cdot 12 \mathrm{H}_{2} \mathrm{O}$. After 7 weeks of growth, the bacterial pathogen $\mathrm{Cmm}$ injection was performed, as described below. When plants reached 10 weeks of growth, plant biomass, mycorrhizal colonization and disease severity index were determined.

\section{Experiment 2: Role of ethylene in Rhizophagus irregularis-induced resistance against $\mathrm{Cmm}$}

Tomato seeds (Solanum lycopersicum L.) of Never ripe ( $\mathrm{Nr}$ ), ethylene-insensitive mutant, and its background Pearson kindly provided by Tomato Genetics Resource Center (University of California, Davis) were used. Before planting the seeds, inoculation with Rhizophagus irregularis (MUCL43194) and non-inoculation were implemented in each genotype. Fourteen replicates of each treatment were distributed randomly in a growth chamber. All growth conditions were the same as the description in experiment 1 . Cmm injection was performed after 7 weeks of plant growth, as described below. Shoot fresh and dry weight, mycorrhizal colonization and disease severity index were examined at 10 weeks of plant growth. 


\section{Bacterial pathogen infection and measurement of disease severity index}

Clavibacter michiganensis subsp. michiganensis (B.01778) from National Collection of Agricultural and Industrial Microorganisms (Hungary) was cultured in LB medium at $27^{\circ} \mathrm{C}$ for $72 \mathrm{~h}$. Bacterial suspension was concentrated by centrifugation at $5,400 \mathrm{~g}$ for $20 \mathrm{~min}$, washed twice and diluted to $10^{9} \mathrm{CFU} / \mathrm{ml}$ using sterile $10 \mathrm{mM} \mathrm{MgCl} 2$. An equal quantity of bacterial suspensions $(50 \mu \mathrm{l})$ was injected into the stem region between the cotyledons of 7-week-old plants with a syringe fitted with a 30-gauge needle while $50 \mu \mathrm{l}$ sterile $10 \mathrm{mM} \mathrm{MgCl}$, solution was used for mock-infected plants (non-Cmm plants). Disease severity was assessed after 7, 14, 17, 21 days post (the pathogen) inoculation (dpi), based on a $0-5$ arbitrary scale as follows: 0 , leaves expressing no wilting; $1, \leq 10 \%$ of leaves expressing wilting; $2,11-25 \%$ of leaves with wilting; 3, sectored wilting, 26-49\% of leaves expressing wilting associated with chlorosis; 4, pronounced collapse as leaf extended, $50-74 \%$ of leaves expressing wilting; 5, whole plant wilted. A mean disease severity index (DSI) was calculated for each treatment from the score of 30 plants (three replicates of 10 plants for each treatment) in experiment 1 and 14 plants (two replicates of 7 plants per treatment) in experiment 2 using the formula [32]: DSI $(\%)=\left[\left(\sum\right.\right.$ rating no. $\times$ no. of plants in rating $)$ $\times 100 \%] /($ total no. of plants $\times$ highest rating).

\section{Measurement of shoot fresh and dry weight}

Shoot fresh weight from four different ten-week plants per treatment was weighed, then dried in a hot-air oven at $70{ }^{\circ} \mathrm{C}$ for 2 days to have their dry weight.

\section{Assessment of AMF root colonization}

After 10 weeks of growth, root samples were collected, then cleaned and stained according to the method using ink and vinegar [41]. The percentage of mycorrhizal colonization was assessed by the gridline intersection method [13]. Briefly, the root sample cut into $1 \mathrm{~cm}$ root segments was dispersed randomly in a square Petri dish $(10.2 \times 10.2 \mathrm{~cm})$ with gridlines on the dish bottom. Horizontal and vertical gridlines were observed under a stereomicroscope at $\times 100$ magnification to record the absence or presence of AMF infection at each point where the root segments intersected a line. Four replications per a root sample were implemented, and four root samples from four plants each treatment were used.

\section{Statistical analysis}

Statistical analysis was carried out using SAS 9.1 statistical package. Our data were analysed by one-way analysis of variance (ANOVA) followed by Duncan posthoc test at $\mathrm{P}<0.05$. 


\section{RESULTS}

\section{Rhizophagus irregularis induces plant resistance against Cmm effectively among AMF isolates tested}

After 10 weeks of growth, mycorrhizal colonization rate among AM treatments was significantly different (Fig. 1A) while no substantial differences in plant growth responses of all treatments could be observed (data not shown). The highest colonization level (64.5\%) was gained by Rhizophagus irregularis (MUCL43194), the most widespread and most frequently studied AM fungal species while the lowest colonization was found by Gigaspora margarita (37.4\%).

In addition to different responses to mycorrhizal inoculation, three levels of responses to the bacterial disease were also recognized at 17 and 21 dpi although no significant differences in DSI among treatments were found at 7 and 14 dpi (Fig. 1B). Tomato plants inoculated with Rhizophagus irregularis showed both the highest colonization and the highest induced resistance to $\mathrm{Cmm}$ after 21 days of bacterial infection, while the effect of other isolates (Funneliformis mosseae, Gigaspora margarita and Claroideoglomus claroideum) on the mycorrhizal colonization and the induced resistance were intermediate and high, respectively. Surprisingly, plants inoculated with Gigaspora margarita showed the lower colonization than other tested isolates, whereas the high resistance to $\mathrm{Cmm}$ in that treatment (Gigaspora margarita) was observed. No significant differences in plant biomass of all treatments were found but Cmm resistance induced by Funneliformis mosseae, Gigaspora margarita, Claroideoglomus claroideum, particularly Rhizophagus irregularis was observed, suggesting that the MIR was not related to plant growth enhanced by AMF.

\section{Rhizophagus irregularis induced resistance is dependent on ethylene}

In order to explore the involvement of ET in mycorrhiza-induced resistance, we used Never ripe (Nr), whose one member of the ET receptor gene family is mutated, resulting in ET insensitivity in tomato plants [20] and its corresponding background (Pearson), while Rhizophagus irregularis was chosen as AMF inoculation based on the result of our experiment 1 . Ri-induced resistance was also observed in the background plants inoculated by Ri at 7, 14, 17, 21 dpi, confirming the result of our experiment 1 (Fig. 2). In addition, ET insensitivity limited disease development of $\mathrm{Cmm}$ due to the fact that DSI of Nr plants was considerably lower than that of the Pearson background during three weeks of Cmm infection. Remarkably, insensitivity of ET in Nr plants colonized with Ri eliminated the MIR against Cmm, when its DSI was similar to that of Pearson plants without Ri inoculation over the course of Cmm infection. These suggest that ET plays a key role in Ri-induced resistance against $\mathrm{Cmm}$.

Noticeably, AM colonization failed to increase shoot fresh and dry weight in plants in our experimental conditions, where no remarkable differences in shoot fresh and dry weight between Pearson and Pearson $+\mathrm{Ri}, \mathrm{Nr}$ and $\mathrm{Nr}+\mathrm{Ri}$ were detected (Table 1). 

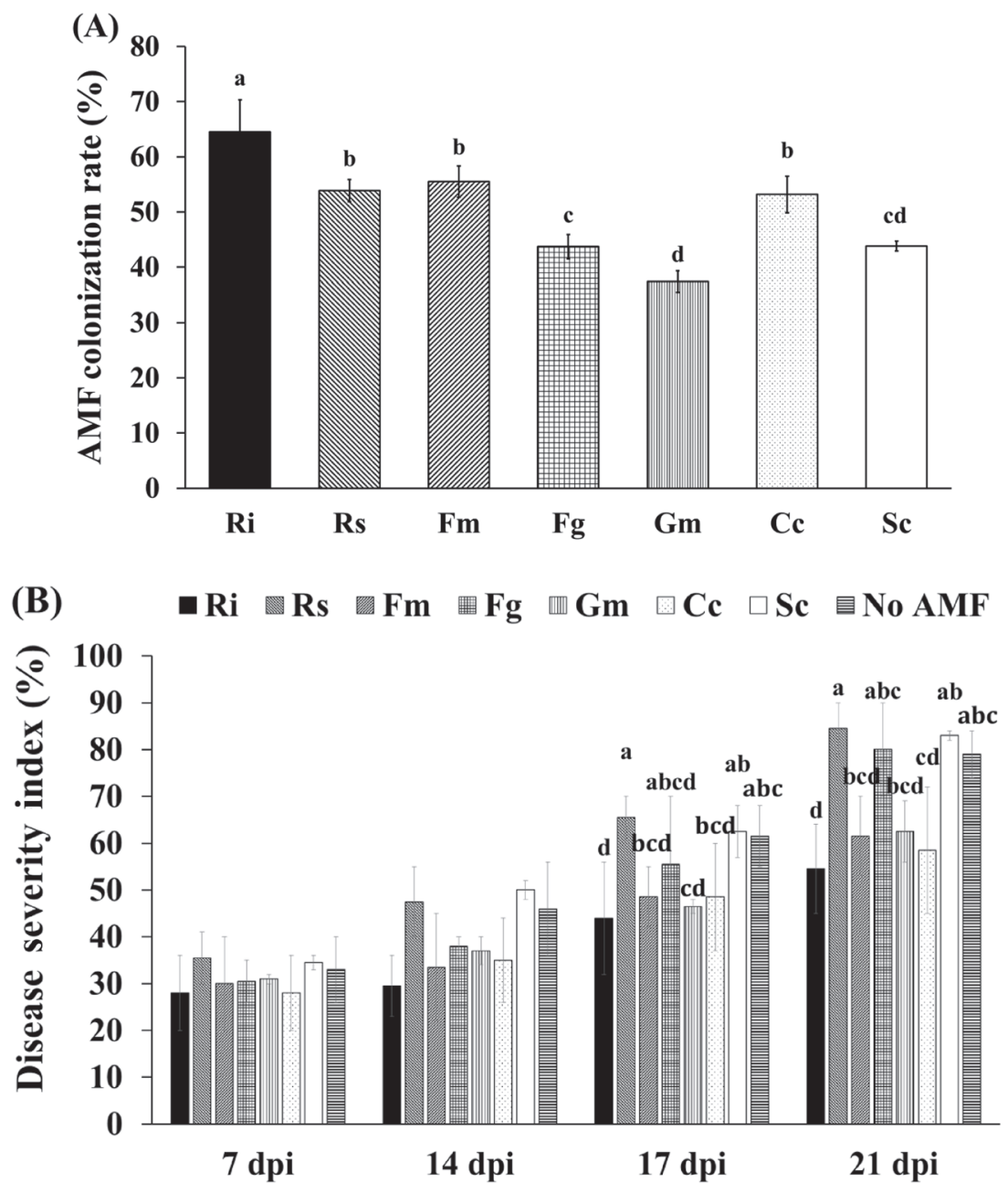

Fig. 1. Arbuscular mycorrhizal fungi (AMF) colonization rate (A) after 10 weeks of growth and disease severity index (DSI) (B) in arbuscular mycorrhizal (AM) and non-AM tomato plants at 7, 14, 17, 21 days post inoculation of Cmm (dpi). Ri, Rizophagus irregularis MUCL 43194; Rs, Rhizophagus sp. MUCL 43204; Fm, Funneliformis mosseae BEG 12; Fg, Funneliformis geosporum BEG 11; Gm, Gigaspora margarita BEG 34; Cc, Claroideoglomus claroideum BEG 23; Sc, Septoglomus constrictum. Bars present means \pm Standard Error. No significant differences in DSI among treatments at 7 and 14 dpi. Different letters denote significant differences in DSI among treatments at 17 and $21 \mathrm{dpi}$

Cmm significantly decreased shoot fresh and dry weight in $\mathrm{Nr}$ mutant and its background but the more pronounced reduction in shoot dry weight was found in the treatment $\mathrm{Nr}+\mathrm{Ri}+\mathrm{Cmm}$. Interestingly, $\mathrm{AM}$ colonization rate in $\mathrm{Nr}+\mathrm{Ri}$ increased, as compared to Pearson $+\mathrm{Ri}$, whilst the percentage was most severely decreased in $\mathrm{Nr}+\mathrm{Ri}+\mathrm{Cmm}$. 
Table 1

Shoot fresh and dry weight, AM colonization rate in Never ripe (Nr) tomato mutant and its background Pearson with or without Clavibacter michiganensis subsp. michiganensis (Cmm) infection

\begin{tabular}{|l|c|c|c|}
\hline \multicolumn{1}{|c|}{ Treatment } & Shoot fresh weight $(\mathrm{g})$ & Shoot dry weight $(\mathrm{g})$ & AM colonization (\%) \\
\hline Pearson & $26.35 \pm 2.6^{\mathrm{ab}}$ & $1.97 \pm 0.1^{\mathrm{a}}$ & 0 \\
\hline Pearson $+\mathrm{Cmm}$ & $13.95 \pm 1.7^{\mathrm{b}}$ & $0.93 \pm 0.2^{\mathrm{b}}$ & 0 \\
\hline Pearson $+\mathrm{Ri}$ & $28.76 \pm 1.9^{\mathrm{a}}$ & $2.10 \pm 0.2^{\mathrm{a}}$ & $54.0 \pm 0.7^{\mathrm{b}}$ \\
\hline Pearson $+\mathrm{Ri}+\mathrm{Cmm}$ & $14.40 \pm 2.2^{\mathrm{b}}$ & $1.04 \pm 0.2^{\mathrm{b}}$ & $52.5 \pm 1.1^{\mathrm{b}}$ \\
\hline \multicolumn{3}{|l}{} \\
\hline $\mathrm{Nr}$ & $20.74 \pm 1.5^{\mathrm{A}}$ & $1.44 \pm 0.2^{\mathrm{A}}$ & 0 \\
\hline $\mathrm{Nr}+\mathrm{Cmm}$ & $13.69 \pm 1.0^{\mathrm{B}}$ & $1.09 \pm 0.1^{\mathrm{B}}$ & 0 \\
\hline $\mathrm{Nr}+\mathrm{Ri}$ & $20.11 \pm 1.4^{\mathrm{A}}$ & $1.52 \pm 0.1^{\mathrm{A}}$ & $65.1 \pm 0.3^{\mathrm{b}}$ \\
\hline $\mathrm{Nr}+\mathrm{Ri}+\mathrm{Cmm}$ & $10.06 \pm 1.3^{\mathrm{B}}$ & $0.75 \pm 0.1^{\mathrm{C}}$ & $38.5 \pm 2.1^{\mathrm{c}}$ \\
\hline
\end{tabular}

AM - arbuscular mycorrhizal; Ri - Rhizophagus irregularis. Parameters were shown as the mean value of four replicates \pm Standard Error. Different regular and capital letters each column express significant differences in shoot fresh and dry weight of the background Pearson and $\mathrm{Nr}$ mutant, respectively. Different letters in AM colonization column indicate significant differences among plants pretreated by Ri.

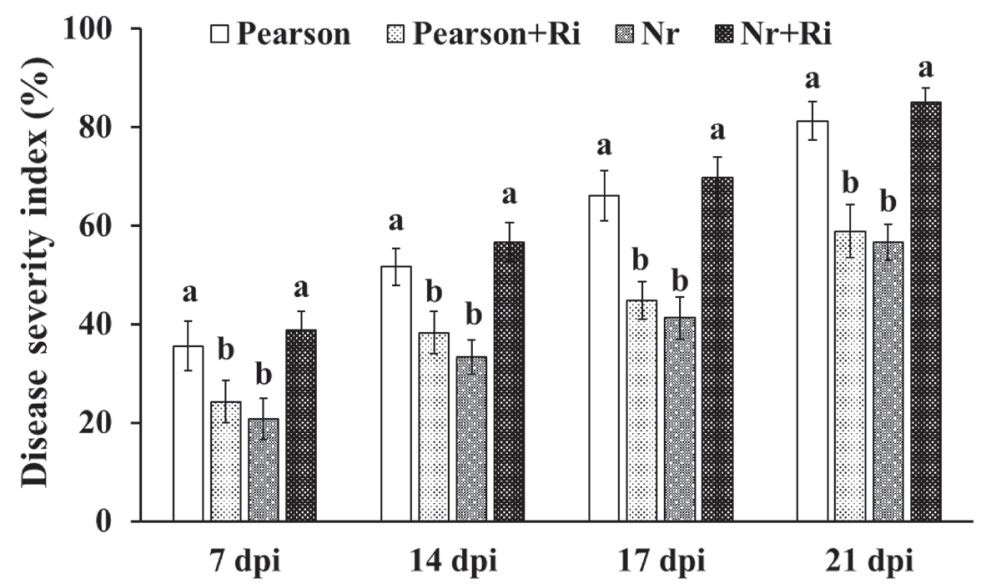

Fig. 2. Disease severity index (DSI) of arbuscular mycorrhizal (AM) and non-AM tomato plants at 7, 14, 17, 21 days post inoculation (dpi) of Clavibacter michiganensis subsp. michiganensis (Cmm) in ethylene insensitive mutant (Nr) and its wild-type (Pearson). Ri, Rhizophagus irregularis MUCL 43194. Bars present means \pm Standard Error. Different letters denote significant differences in DSI among treatments at 7 , 14,17 and $21 \mathrm{dpi}$, respectively 


\section{DISCUSSION}

Different AM colonization rate of the isolates found in our results reflects various AM colonization strategies. Rhizophagus isolates, high colonization in the present study, produce an extensive hyphal network providing a competitive advantage over other isolates [37], whereas Gigaspora sp. shows a lower capacity in that process as we also recognized it, moreover, its re-establishment of mycelium through their anastomoses also offers a smaller capacity to colonize the roots compared to other species [31]. Other tested strains in our work, namely Rhizophagus sp. (MUCL 43204), Claroideoglomus claroideum (BEG 23) and Funelliformis mosseae (BEG 12) had an intermediate level of colonization, confirming that tomato is intermediate in mycorrhizal dependency [28].

It is known that AM symbiosis could enhance plant resistance against a wide range of viral, bacterial and fungal pathogens $[10,12,21,23,38]$, but our report is the only one regarding the bacterial disease caused by $\mathrm{Cmm}$. The present study showed that $\mathrm{Ri}$ induced the most effective systemic resistance against $\mathrm{Cmm}$ among seven AMF isolates tested. Different mechanisms are proposed to interpret the role of AMF in plant protection. During mycorrhization, AMF-induced modulation of plant defence responses takes place to achieve a functional symbiosis, leading to activating host immunity locally as well as systemically, called primed state of the plant. This state allows the plant to trigger defence responses more quickly and effectively upon being attacked by potential enemies [17]. Furthermore, a remarkable transcriptional reprogramming, significant alterations in the hormonal balance, primary and secondary metabolisms occur in the host plants during mycorrhization [17, 22]. Transcriptional changes in both roots and shoots in Medicago truncatula plants inoculated by Rhizophagus irregularis (syn. Glomus intraradices), Gigaspora gigantea, Glomus versiforme resulted in an increased resistance to the shoot pathogen Xanthomonas campestris pv. alfalfae [21]. Even, underground common mycorrhizal networks of tomato plants pretreated by Funneliformis mosseae (syn. Glomus mosseae) induced resistance of neighbours against Alternaria solani [39]. More recently, AMF-primed resistance to Alternaria solani has been proved in tomato plants treated with Funneliformis mosseae when they showed enhanced expressions of important defense genes and higher activities of defense-related enzymes as compared to nonAM plants [38].

It is believed that AMF can enhance its host plant nutrient and growth but improved mycorrhizal plant growth was not observed in both of our experiments, perhaps due to the fact that plants were cultivated in pots under suboptimal conditions. Thus, the protective role of AMF was associated with mechanisms other than a better plant fitness, most probably linked to plant defenses.

AM colonization rate in ET insensitivity mutant was increased in relation to the Pearson background, which is in line with the results of several studies revealing that ET has detrimental effects on mycorrhizal development in the symbiosis $[11,33]$. It should be noted that the colonization was most profoundly decreased in Never ripe plants with $\mathrm{Ri}$ and $\mathrm{Cmm}$ inoculation, suggesting that $\mathrm{Cmm}$ negatively affected $\mathrm{AM}$ 
development in ET-insensitive mutant. This may be owing to the fact that $\mathrm{Cmm}$ weakened plant fitness, leading to decreasing photosynthate source for the mycorrhizal symbiont, and/or Cmm activated the plant defense system that consequently inhibited the mycorrhizal development. Similarly, the aboveground pathogen Colletotrichum gloeosporioides decreased belowground AM colonization in Phaseolus vulgaris due to its activation of plant defense responses [5].

ET, a main component of plant defense signals, is generated during microbe-plant interactions. ET can act as a crucial regulator of plant immunity $[6,40]$. Our analyzed results indicated that on the one hand, impaired perception of ET decreased significantly the development of wilt symptoms caused by $\mathrm{Cmm}$. This is in accordance with earlier studies revealing that ET in the host plant is crucial in the regulation of the susceptibility to $\mathrm{Cmm}$ in tomato plants $[4,34,35]$. On the other hand, ET is required for MIR against $\mathrm{Cmm}$ due to the fact that $\mathrm{Nr}$ plants pretreated by Ri did not induce resistance against this bacterial pathogen. Previous reports has emphasized a necessary role of Jasmonate-regulated pathway in MIR against diferent pathogens in several plants [25-27, 30,38]. Nonetheless, it is worth noting that there is little information about the involvement of ET signaling pathway in MIR. Our result is the first observation of MIR against Cmm mediated by ET. Numerous studies demonstrated that together with Jasmonate, ET plays a central role in control of induced resistance by various beneficial microbes such as Bacillus pumilus SE34 and Pseudomonas fluorescens 89B61 [43] in tomato plants, Trichoderma harzianum T39 [19], Pseudomonas fluorescens Q2-87 [42], Pseudomonas protegens CHA0 [16], Penicillium sp. GP16-2 [15] in Arabidopsis. In fact, ET is able to stimulate production of distinct pathogenesis-related (PR) proteins or phytoalexins derived from the phenylpropanoid pathway leading to ridification of cell walls in a wide range of plant species [1, 3], thus enhancing plant resistance against pathogens. Additionally, JAand ET-signaling pathway often operate synergistically to induce the effector genes of induced defense responses [8, 29,36].

In conclusion, our results demonstrate that AM colonization could induce systemic plant resistance against $\mathrm{Cmm}$; however, its efficiency depends on specific isolate of AMF, and ET signaling pathway is required for MIR against Cmm. Further studies are necessary to elucidate the mechanisms involved the induced resistance to Cmm.

\section{ACKNOWLEDGEMENTS}

The study was funded by Stipendium Hungaricum and Research Centre of Excellence 1476-4/2016/ FEKUT. The authors thank Dr. Turoczi Gyorgy, Institute of Plant Protection, Szent István University, for useful advices during the study. We also would like to thank Tomato Genetics Resource Center (Univeristy of California, UC) for kindly providing tomato seeds of Never ripe mutant and its background Pearson. 


\section{REFERENCES}

1. Abeles, F. B., Morgan, P. W., Saltveit, M. E. (1992) Ethylene in Plant Biology. Ed. 2. Academic Press, New York.

2. Adie, B., Chico, J. M., Rubio-Somoza, I., Solano, R. (2007) Modulation of plant defenses by ethylene. J. Plant Growth Regul. 26, 160-177.

3. Arshad, M., Frankenberger, W. T. (2002) Ethylene, Agricultural Sources and Applications. New York, Kluwer/Plenum.

4. Balaji, V., Mayrose, M., Sherf, O., Jacob-Hirsch, J., Eichenlaub, R., Iraki, N., Manulis-Sasson, S., Rechavi, G., Barash, I., Sessa, G. (2008) Tomato transcriptional changes in response to Clavibacter michiganensis subsp. michiganensis reveal a role for ethylene in disease development. Plant Physiol. 146, 1797-1809.

5. Ballhorn, D. J., Younginger, B. S., Kautz, S. (2014) An aboveground pathogen inhibits belowground rhizobia and arbuscular mycorrhizal fungi in Phaseolus vulgaris. BMC Plant Biol. 14, 321.

6. Broekaert, W. F., Delaure, S. L., De Bolle, M. F. C., Cammuel, B. P. A. (2006) The role of ethylene in host-pathogen interactions. Annu. Rev. Phytopathol. 44, 393-416.

7. Davis, M. J., Gillespie, J. A., Vidaver, A. K., Harris, R. W. (1984) Clavibacter: a new genus containing some phytopathogenic coryneform bacteria, including Clavibacter xyli subsp. xyli sp. nov., subsp. nov. and Clavibacter xyli subsp. cynodontis subsp. nov., pathogens that cause ratoon stunting disease of sugarcane and bermudagrass stunting disease. Int. J. Syst. Bacteriol. 34, 107-117.

8. Ellis, C., Turner, J. G. (2001) The Arabidopsis mutant cev1 has constitutively active jasmonate and ethylene signal pathways and enhanced resistance to pathogens. Plant Cell 13, 1025-1033.

9. Filion, M., ST-Arnaud, M., Fortin, J. A. (1999) Direct interaction between the arbuscular mycorrhizal fungus Glomus intraradices and different rhizosphere microorganisms. New Phytol. 141, 525-533.

10. Fiorilli, V., Catoni, M., Francia, D., Cardinale, F., Lanfranco, L. (2011). The arbuscular mycorrhizal symbiosis reduces disease severity in tomato plants infected by Botrytis cinerea. J. Plant Pathol. 93, 237-242.

11. Fracetto, G. G. M., Peres, L. E. P., Lambais, M. R. (2017) Gene expression analyses in tomato near isogenic lines provide evidence for ethylene and abscisic acid biosynthesis fine-tuning during arbuscular mycorrhiza development. Arch. Microbiol. 199, 787-798.

12. Fritz, M., Jakobsen, I., Langkjaer, M. F., Thordal-Christensen, H., Pons-Kühnemann, J. (2006) Arbuscular mycorrhiza reduces susceptibility of tomato to Alternaria solani. Mycorrhiza 16, 413-419.

13. Giovannetti, M., Mosse, B. (1980) An evaluation of techniques for measuring vesicular-arbuscular mycorrhizal infection in roots. New Phytol. 84, 489-500.

14. Hewitt, E. J. (1966) Sand and Water Culture Methods Used in the Study of Plant Nutrition. 2nd edn. London: Commonwealth Agricultural Bureau.

15. Hossain, M. M., Sultana, F., Kubota, M., Hyakumachi, M. (2008) Differential inducible defense mechanisms against bacterial speck pathogen in Arabidopsis thaliana by plant-growth-promotingfungus Penicillium sp. GP16-2 and its cell free filtrate. Plant Soil 304, 227-239.

16. Iavicoli, A., Boutet, E., Buchala, A., Métraux, J. P. (2003) Induced systemic resistance in Arabidopsis thaliana in response to root inoculation with Pseudomonas fluorescens CHA0. Mol. Plant-Microbe Interact. 16, 851-858.

17. Jung, S. C., Martinez-Medina, A., Lopez-Raez, J. A., Pozo, M. J. (2012) Mycorrhiza-induced resistance and priming of plant defenses. J. Chem. Ecol. 38, 651-664.

18. Khatabi, B., Schäfer, P. (2012) Ethylene in mutualistic symbioses. Plant Signal. Behav. 7, 1634-1638.

19. Korolev, N., David, D. R., Elad, Y. (2008) The role of phytohormones in basal resistance and Trichoderma induced systemic resistance to Botrytis cinerea in Arabidopsis thaliana. Biocontrol 53, 667-683.

20. Lanahan, M. B., Yen, H. C., Giovannoni, J. J., Klee, H. J. (1994) The never ripe mutation blocks ethylene perception in tomato. Plant Cell 6, 521-530. 
21. Liu, J., Maldonado-Mendoza, I., Lopez-Meyer, M., Cheung, F., Town, C. D., Harrison, M. J. (2007) Arbuscular mycorrhizal symbiosis is accompanied by local and systemic alterations in gene expression and an increase in disease resistance in the shoots. Plant J. 50, 529-544.

22. López-Ráez, J. A., Verhage, A., Fernández, I., García, J. M., Azcón-Aguilar, C., Flors, V., Pozo, M. J. (2010) Hormonal and transcriptional profiles highlight common and differential host responses to arbuscular mycorrhizal fungi and the regulation of the oxylipin pathway. J. Exp. Bot. 61, 2589-2601.

23. Maffei, G., Miozzi, L., Fiorilli, V., Novero, M., Lanfranco, L., Accotto, G. P. (2014) The arbuscular mycorrhizal symbiosis attenuates symptom severity and reduces virus concentration in tomato infected by Tomato yellow leaf curl Sardinia virus (TYLCSV). Mycorrhiza 24, 179-186.

24. Møller, K., Kristensen, K., Yohalem, D., Larsen, J. (2009) Biological management of gray mold in pot roses by coinoculation of the biocontrol agent Ulocladium atrum and the mycorrhizal fungus Glomus mosseae. Biol. Control 49, 120-125.

25. Mora-Romero, G. A., Gonzalez-Ortiz, M. A., Quiroz-Figueroa, F., Calderon-Vazquez, C. L., MedinaGodoy, S., Maldonado-Mendoza, I., Arroyo-Becerra, A., Perez-Torres, A., Alatorre-Cobos, F., Sanchez, F., Lopez-Meyer, M. (2015) PvLOX2 silencing in common bean roots impairs arbuscular mycorrhiza-induced resistance without affecting symbiosis establishment. Funct. Plant Biol. 42, $18-30$.

26. Nair, A., Kolet, S. P., Thulasiram, H. V., Bhargava, S. (2015) Systemic jasmonic acid modulation in mycorrhizal tomato plants and its role in induced resistance against Alternaria alternata. Plant Biol. $17,625-631$.

27. Nair, A., Kolet, S. P., Thulasiram, H. V., Bhargava, S. (2015) Role of methyl jasmonate in the expression of mycorrhizal induced resistance against Fusarium oxysporum in tomato plants. Physiol. Mol. Plant Pathol. 92, 139-145.

28. Plenchette, C., Fortin, J. A., Furlan, V. (1983) Growth responses of several plant species to mycorrhizae in a soil of moderate P-fertility: I. Mycorrhizal dependency under field conditions. Plant Soil 70, 199-209.

29. Pieterse, C. M., Van Loon, L. C. (1999) Salicylic-acid-independent plant defence pathways. Trends Plant Sci. 4, 52-58.

30. Pozo, M. J., Jung, S. C., López-Ráez, J. A., Azcón-Aguilar, C. (2010) Impact of arbuscular mycorrhizal symbiosis on plant response to biotic stress: The role of plant defence mechanisms. In: Koltai, H., Kapulnik, Y. (eds), Arbuscular Mycorrhizas: Physiology and Function. Springer Netherlands, Dordrecht, pp. 193-207.

31. de la Providencia, I. E., de Souza, F. A., Fernández, F., Delmas, N. S., Declerck, S. (2005) Arbuscular mycorrhizal fungi reveal distinct patterns of anastomosis formation and hyphal healing mechanisms between different phylogenic groups. New Phytol. 165, 261-271.

32. Raupach, G. S., Liu, L., Murphy, J. F., Tuzun, S. T., Kloepper, J. W. (1996) Induced systemic resistance in cucumber and tomato against cucumber mosaic cucumovirus using plant growthpromoting rhizobacteria (PGPR). Plant Dis. 80, 891-894.

33. Santos, R. T. d. 1., Rosales, N. M., Ocampo, J. A., García-Garrido, J. M. (2016) Ethylene alleviates the suppressive effect of phosphate on arbuscular mycorrhiza formation. J. Plant Growth Regul. 35, 611-617.

34. Savidor, A., Teper, D., Gartemann, K. H., Eichenlaub, R., Chalupowicz, L., Manulis-Sasson, S., Barash, I., Tews, H., Mayer, K., Giannone, R. J., Hettich, R. L., Sessa, G. (2012) The Clavibacter michiganensis subsp. michiganensis-Tomato interactome reveals the perception of pathogen by the host and suggests mechanisms of infection. J. Proteome Res. 11, 736-750.

35. Savidor, A., Chalupowicz, L., Teper, D., Gartemann, K. H., Eichenlaub, R., Manulis-Sasson, S., Barash, I., Sessa, G. (2014) Clavibacter michiganensis subsp. michiganensis Vatr1 and Vatr2 transcriptional regulators are required for virulence in tomato. Mol. Plant Microbe Interact. 27, 1035-1047.

36. Schenk, P. M., Kazan, K., Wilson, L., Anderson, J. P., Richmond, T., Somerville, S. C., Manners, J. M. (2000) Coordinated plant defense responses in Arabidopsis revealed by microarray analysis. Proc. Natl Acad. Sci. USA 97, 11655-11660. 
37. Silvani, V. A., Bidondo, L. F., Bompadre, M. J., Colombo, R. P., Pérgola, M., Bompadre, A., Fracchia, S., Godeas, A. (2014) Growth dynamics of geographically different arbuscular mycorrhizal fungal isolates belonging to the 'Rhizophagus clade' under monoxenic conditions. Mycologia 106, 963-975.

38. Song, Y., Chen, D., Lu, K., Sun, Z., Zeng, R. (2015) Enhanced tomato disease resistance primed by arbuscular mycorrhizal fungus. Frontiers in Plant Science 6, 1-13.

39. Song, Y. Y., Zeng, R., Sen, Xu, J. F., Li, J., Shen, X., Yihdego, W. G. (2010) Interplant communication of tomato plants through underground common mycorrhizal networks. PLOS ONE 5.

40. Van Loon, L. C., Geraats, B. P. J., Linthorst, H. J. M. (2006) Ethylene as a modulator of disease resistance in plants. Trends Plant Sci. 11, 184-191.

41. Vierheilig, H., Coughlan, A. P., Wyss, U., Piché, Y. (1998) Ink and vinegar, a simple staining technique for arbuscular-mycorrhizal fungi. Appl. Environ. Microbiol. 64, 5004-5007.

42. Weller, D. M., Mavrodi, D. V., Van Pelt, J. A., Pieterse, C. M. J., Van Loon, L. C., Bakker, P. A. H. M (2012) Induced systemic resistance (ISR) in Arabidopsis thaliana against Pseudomonas syringae pv. tomato by 2,4-diacetylphloroglucinol-producing Pseudomonas fluorescens. Phytopathology 102, 403-412.

43. Yan, Z., Reddy, M. S., Ryu, C.-M., McInroy, J. A., Wilson, M., Kloepper, J. W. (2002) Induced systemic protection against tomato late blight elicited by plant growth-promoting rhizobacteria. Phytopathology 92, 1329-1333. 